\title{
Relationship between head and neck injuries and helmet use in fatal motorcycle and moped crashes in Denmark
}

\author{
Lars Uhrenholt',2, Catrine Kudahl Thomsen', Kasper Hansen 1,2,3,4, Lene Warner Thorup Boel',2, \\ Michael D Freeman ${ }^{5}$
}

'Department of Forensic Medicine, Aarhus University, 8200 Aarhus, Denmark

2Paraclinical Imaging Studies Group (PIMAS), Aarhus University, 8200 Aarhus, Denmark

${ }^{3}$ Section of Zoophysiology, Department of Bioscience, Aarhus University, 8000 Aarhus C, Denmark

${ }^{4}$ Comparative Medicine Lab, Department of Clinical Medicine, Aarhus University, 8200 Aarhus N, Denmark

${ }^{5}$ Care and Primary Health Research Institute, Faculty of Health, Medicine, and Life Sciences, Maastricht University, 6229 ER Maastricht, The Netherlands

*Corresponding author lu@forens.au.dk

\begin{abstract}
:
Motorcycle- and moped crashes are prevalent in motorised societies and carry a significant risk of serious injury. Whereas helmet use has reduced the frequency and severity of head injuries, the association between helmet use and neck injury risk is less clear. In the present retrospective study, we examined the relationship between helmet use and various types of head and neck injuries resulting from fatal motorcycle and moped crashes during a 20-year period. Eighty-three cases were included of whom 56 were analysed in detail based on their confirmed use/non-use of helmet. Intracranial haemorrhage was the most common finding, followed by CNS disruption and skull fracture. There was a significantly lower prevalence of skull vault fractures and epidural haemorrhage in the helmeted cases. Injuries to the brainstem and cervical spine fracture/dislocation were more common in the helmeted cases, although this was likely a function of higher speeds among motorcycle riders rather than an effect of helmet use per se. Further investigation of these findings require additional detailed information regarding the nature and severity of the crash, as well as helmet use and type, in order to assess non-confounded associations with the anatomical distribution, type and severity of observed head and neck injuries.
\end{abstract}

Keywords:

fatal motorcycle crash, fatal moped crash, helmet, road traffic crash, traffic safety, head injury, neck injury, medicolegal autopsy, post-mortem

\section{INTRODUCTION}

The number of traffic crash-related injuries has been declining in Denmark over the past several decades due to traffic safety initiatives, improved vehicles safety, and legislative actions ${ }^{1}$. The same trend has been observed for fatal traffic crashes, as the number of annual fatalities has declined from approximately 1.200 in the early 1970's to approximately 200 annually in recent years ${ }^{2}$.
Throughout the twenty-year period from 1998-2017 the number of people killed on motorcycles (MC) averaged 20 per year, and ranged from a high of 41 cases in 2008 to 11 cases in both 2012 and 2017 (Figure 1). In 1998, motorcyclists accounted for $4.2 \%$ of all traffic crash fatalities. However, despite the reduction of $\mathrm{MC}$ deaths and the total number of road traffic crash deaths in Denmark this proportion reached a high of $12.3 \%$ by 2016 (Figure 2).

The number of people killed on mopeds was relatively stable from 19982004 at approximately 40 each year. Between 2005-2010 there was large

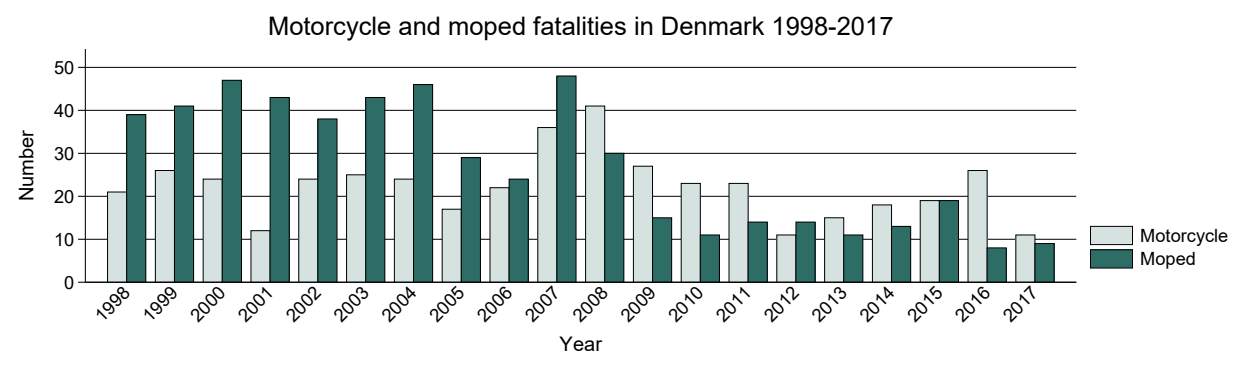

Figure 1: Motorcycle and moped fatalities in Denmark 1998-2017. A general decline in the number of people killed driving a motorcycle or moped was observed 

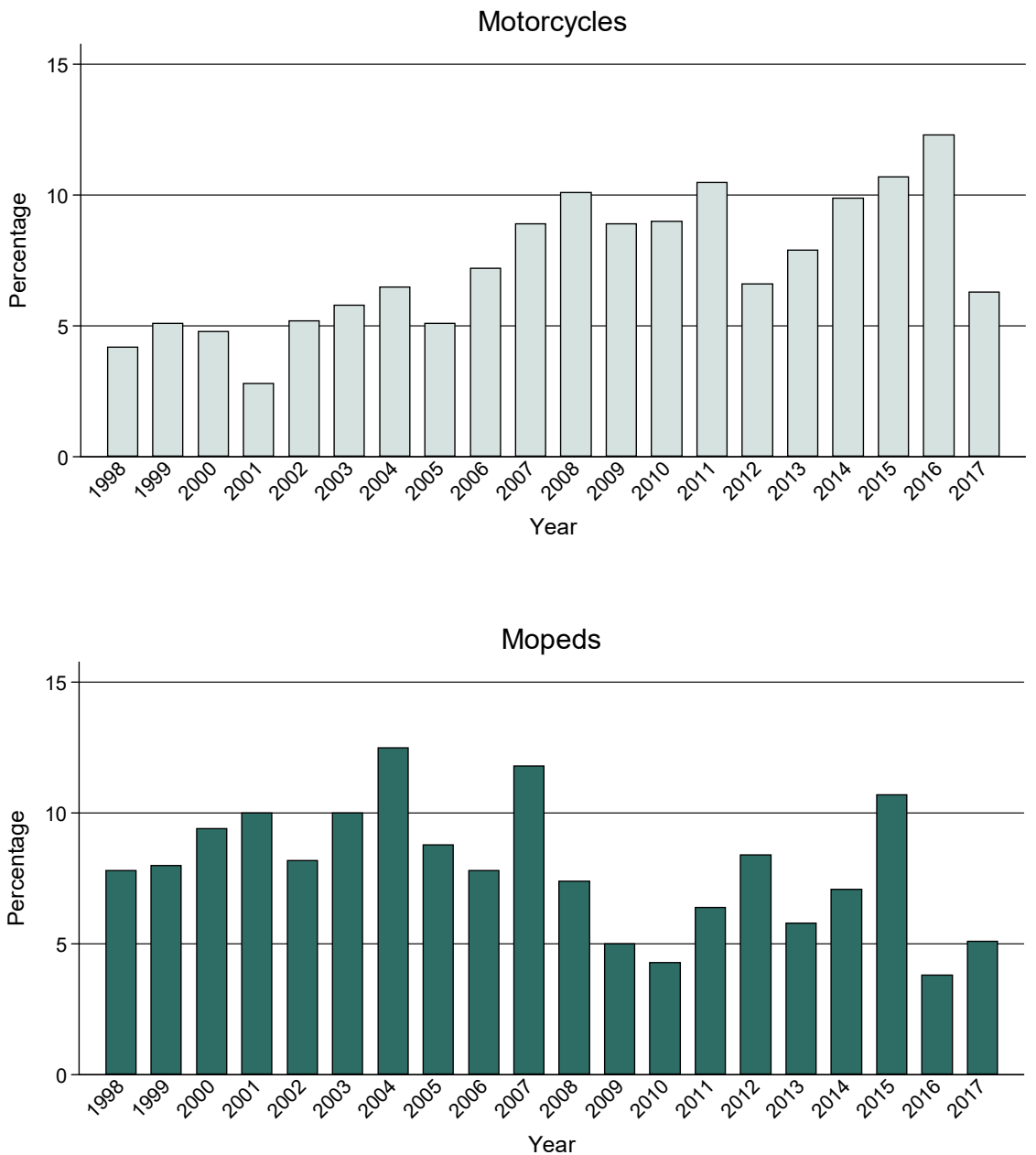

Figure 2: Proportion of all road traffic crash deaths by mode of transportation 1998-2017. During the recent twenty-year study period from 1998 to 2017 , a general increase in the proportion of deaths on motorcycles could be observed, whereas a decline was observed for the moped drivers.

fluctuation in the number of deaths from year to year, but since 2010 a stable average of approximately 12 moped rider deaths per year has been reached (Figure 1). Whilst accounting for $7.8 \%$ of all crash fatalities in 1998 , and $12.5 \%$ in 2004 , the proportion of deaths occurring on mopeds declined to $3.8 \%$ in 2016, which was the lowest prevalence throughout the study period of 20 years (Figure 2).

Serious head and neck injuries are common consequences of MC and moped crashes, irrespective of the use or non-use of a helmet ${ }^{3}$. Although helmets have been shown to reduce the risk of head injuries for motorcyclists ${ }^{3 ; 4}$, some researchers have theorised that there is an increased risk of injury at the craniocervical junction for helmet users ${ }^{5 ; 6}$. However, a Cochrane review from 2008 found no support for this hypothesis ${ }^{3}$.

The use of helmet for MC and moped riders is mandated by law in Denmark, and the compliance is reportedly as high as $97 \%$. In contrast with this high rate of helmet usage among all riders, approximately one fifth of MC or moped riders who are severely injured or killed in a crash in Denmark are unhelmeted ${ }^{2}$. While it is intuitive that there is a higher prevalence of helmet non-use among the most severely injured riders, at the present, no detailed information of the effects of helmet use and non-use in fatal MC and moped crashes in Denmark exist. In the present study we set out to examine the pathological findings and other factors in a group of MC and moped riders who died in a traffic crash, and to analyse differences between helmeted and unhelmeted riders.

\section{EXPERIMENTAL PROCEDURES}

\section{Study data}

This retrospective autopsy study included all cases of fatal traffic crashes involving a MC or moped, and which were autopsied at the Department of Forensic Medicine, Aarhus University, Denmark, in the period 1998-2017. The study population was identified by searching an internal database containing all autopsies performed at the department. The database search was based on the following specific criteria; years 1998-2017, manner of death classified as accident, activity during trauma included driving a MC or moped or being a passenger on a MC or moped. An additional search involving other relevant manners of death (i.e. natural, suicide and homicide) revealed no additional cases. A total of 89 cases were found which satisfied 
the inclusion criteria, 6 of which were excluded for the following reasons (leaving 83): one was an unborn fetus, in two cases the cause of death was not related to the crash and in three cases there was too little information concerning the circumstances of the death. The autopsy and police reports from the included cases were reviewed and data regarding sex, age, cause of death, mechanism of trauma, type of vehicle, use of helmet and head- and neck injuries were retrieved. Type of vehicle was classified into MC (including motocross) or moped (including $30 \mathrm{cc}$ and $45 \mathrm{cc}$ mopeds, and three-wheeled disability mopeds). Information concerning injuries was retrieved by reading the full autopsy reports and including the specified diagnoses for each case. From 2008 onwards this included observations made from routine postmortem computed tomography (PMCT) scanning of the deceased, whereas PMCT was performed on a case-by-case basis only in the period from 19982007. In cases of inadequate descriptions of the injuries, journalised sketch drawings were used to ensure correct classification. Similarly, documentation of helmet versus no helmet use was available from the police records or the autopsy report. If the use of helmet could not be determined confidently, it was scored as unknown use of helmet and the case was removed from the final statistical analysis. The observed injuries were categorised into main categories and their subgroups, e.g. skull fracture/skull base fracture, and intracranial haemorrhage/subdural hematoma.

\section{Abbreviated injury scale}

In order to evaluate the aggregate severity of injuries in the head and neck, as they related to mortality risk, we relied on Abbreviated Injury Scale (AIS) definitions and severity ranking ${ }^{7: 8}$. This international standard for injury scaling is the foundation for several models of quantification of injury severity including among others the New Injury Severity Score (NISS) ${ }^{9 ; 10}$. A derivative of the NISS is the HNISS (Head -Neck Injury Severity Score), which has previously been used to investigate the mortality risk of head and cervical spine injuries ${ }^{11}$. In order to calculate the HNISS, only the three most serious injuries in the head and cervical spine based on their AIS scores are included. The HNISS is the sum of the square of these three numbers. If at least one of these three figures is an AIS 6 then the HNISS is automatically assigned 75. A mean HNISS was calculated for each group of injuries for the subjects with known use/non-use of helmet (i.e. $n=56$ ).

\section{Statistical analysis}

Data were analysed for the correlation between the observed injuries and helmet use/non-use. Fisher's exact test was used to test for differences between groups with few numbers. ANOVA was used for analysis of variance. The significance level was $p<0.05$. All statistical analyses were performed using Stata ${ }^{\circ} 13$ (StataCorp LP, College Station, USA).

\section{RESULTS}

During 1998-2017, 468 people were killed in a MC/moped crash in the catchment area of the Department of Forensic Medicine, Aarhus University, Denmark ${ }^{12}$. Eighty-nine (19\%) of the decedents were referred for forensic autopsy (and met the inclusion criteria) and a total of 83 cases (93.2\%) were included in this study. There were 77 male and 6 female subjects. Thirty-six $(46.8 \%)$ of the males and $4(66.7 \%)$ of the females used a helmet. In total, there were 40 subjects using a helmet $(48.2 \%$ of all cases, 36 males $/ 4$ females, mean age 38.3 years), 16 subjects not using a helmet (19.3\% of all cases, all males, mean age 41.8 years) and 27 subjects with unknown helmet use (32.5\% of all cases, 25 males/ 2 females, mean age 44.3 years). Motorcyclists were more than twice as likely to have used a helmet compared to moped riders $(p=0.001)$. Thirty-seven (37) cases involved a MC and 46 involved a moped. There were no significant differences between the riding position (driver versus passenger) or the crash opponent and helmet use. The most common riding position was driver $(91.6 \%)$ and the most common crash opponent was a light motorised vehicle (e.g. passenger car) (45.8\%), (Table 1).

The distribution of the main diagnoses found in all the victims autopsied in 1998-2017 ( $\mathrm{n}=83$ ) are summarised in Figure 3. Fractures of the skull were present in 37 cases (44.6\%) and facial fractures in 16 cases (19.3\%). Intracranial bleeding was the most common major diagnosis group, present in 52 cases (62.7\%). Intracranial neuronal tissue damage was present in 43 cases $(51.8 \%)$ and cervical spine injuries were present in 29 cases (34.9\%).

The detailed distribution of head and neck injuries according to helmet use $(n=56)$ is presented in Table 2. This shows that fractures of the skull base and vault were more frequent in the non-helmeted group, with skull vault fractures being statistically significant $(p=0.025)$. Facial fractures were also more frequent in the non-helmeted group, however not significantly different from the helmeted cases. Intracranial bleeding was the most

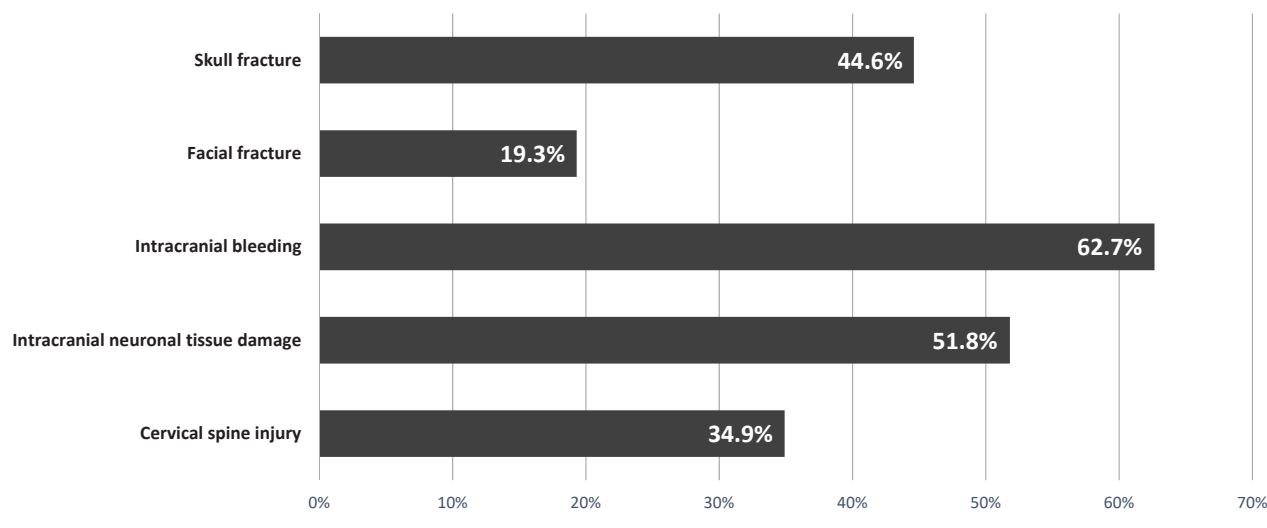

Figure 3: Distribution of major diagnosis groups $(n=83)$. This figure illustrates the distribution of the most common groups of diagnoses observed among fatal moped and motorcycle deaths in the years 1998-2017. 
common major diagnosis group of all affecting $36 / 56$ cases and was more frequent in the non-helmeted group, with the exception of subarachnoid and interventricular haemorrhage. Only epidural haemorrhage was significantly more common in the no helmet group $(p=0.020)$. Intracranial neuronal tissue damage was present in $34 / 56$ cases with no significant differences between subgroups of diagnoses. Although these injuries were generally more common in the no helmet group, cerebellar and brainstem injuries were more frequent among subjects using helmets. Furthermore, a subgroup of brainstem injuries included six cases of medulla oblongata rupture which was exclusively identified in the helmeted subject group $(p=0.168)$. Cervical spine injury was present in 21/56 cases and all subgroups including dislocation, fracture, spinal cord injury and intramuscular haemorrhage were more common in the helmeted subjects, with dislocations only reaching a statistically significant difference $(p=0.048)$.

The distribution of fractures of the skull and face was examined in detail according to the involvement of specific bones and the correlation to helmet use. However, as the involvement of specific bones was not consistently noted in the forensic reports, their distribution could not be determined confidently.

The calculated HNISS scores for each of the 56 subjects showed a mean score of 28.7 with a median of 22.0. There were no significant differences in the HNISS score between helmeted (mean 26.7) and unhelmeted subjects (mean 33.8) ( $p=0.381$ ). The helmeted MC riders had a HNISS of 29.9 versus 11.5 for the unhelmeted riders, whereas the helmeted moped riders had a NHISS of 21.3 versus 36.9 for the unhelmeted riders (none were statistically significant). The presence of a skull fracture, intracranial bleeding or intracranial neuronal tissue damage correlated significantly to an increased HNISS score, with the exception of intracerebral haemorrhage. In the cervical spine, only dislocation injuries showed a significant correlation to an increased HNISS score (Table 3).

\section{DISCUSSION}

This study reviewed 83 cases of fatal traffic crashes involving a motorcycle or moped during a 20 years period. The use of a helmet was significantly more common among motorcyclists compared to moped riders, although usage could be determined in only 56 of the 83 cases. In the helmeted group cervical spine dislocation was significantly more common, whereas skull vault fractures and epidural haemorrhage was significantly more common in deceased not wearing a helmet. Intracranial bleeding was the most common diagnosis group of all, followed by intracranial neuronal tissue damage and fractures of the skull. Injuries to the head (e.g. skull fractures, facial fracture, intracranial bleeding or neuronal tissue damage) and cervical spine dislocations all correlated to an increase in the HNISS score.

\section{Head and face injuries}

Injuries to the head were very common in our study. Based on the distribution of head- and neck injuries according to helmet use injuries were relatively more frequent in the no helmet group (Table 2). Auman et al. ${ }^{13}$ found that motorcyclists wearing helmets in fatal crashes were significantly less likely to suffer from traumatic brain injuries than motorcyclists not wearing helmets (OR $0.31 ; 95 \% \mathrm{Cl}=0.14-0.68)$. Similarly, an autopsy study by Hitosugi et al. ${ }^{14}$ on fatal motorcyclist and bicyclist crashes found skull vault fractures, subdural and intracranial hematomas to be significantly more common among non-helmeted riders. The Cochrane review of the role of helmets preventing injuries in motorcycle crashes by Liu et al. ${ }^{3 ; 3}$ estimated a reduced risk of head injury by $69 \%$ and death by $42 \%$. Hence, our findings are consistent with the results of previous studies regarding a reduced incidence rate of head injuries in helmeted road users.

As expected, the subjects in our population suffered severe and

Table 1: Study population characteristics $(n=83)$

\begin{tabular}{|c|c|c|c|c|}
\hline & Helmet $(n=40)$ & No helmet $(n=16)$ & p-value* & Unknown ( $n=27)$ \\
\hline Sex & & & $0.315 *$ & \\
\hline Male (77) & $36(46.8 \%)$ & $16(20.8 \%)$ & & $25(32.5 \%)$ \\
\hline Female (6) & $4(66.7 \%)$ & 0 & & $2(33.3 \%)$ \\
\hline Age (mean; range ; SD) & $38.3 ;[15-77] ; 15.1$ & $41.8 ;[16-83] ; 20.0$ & $0.481^{* *}$ & $44.3 ;[17-89] ; 19.2$ \\
\hline Vehicle & & & $0.001 *$ & \\
\hline Motorcycle (MC) (37) & $25(67.6 \%)$ & $2(5.4 \%)$ & & $10(27.0 \%)$ \\
\hline Moped (46) & $15(32.6 \%)$ & $14(30.4 \%)$ & & $17(37.0 \%)$ \\
\hline Riding position & & & $0.617^{*}$ & \\
\hline Driver (76) & $37(42.9 \%)$ & $14(18.4 \%)$ & & $25(32.9 \%)$ \\
\hline Passenger (7) & $3(42.9 \%)$ & $2(28.6 \%)$ & & $2(28.6 \%)$ \\
\hline Crash opponent & & & $0.065 *$ & \\
\hline No opponent (14) & $6(42.9 \%)$ & $3(21.4 \%)$ & & $5(35.7 \%)$ \\
\hline Light motorized vehicle (38) & $25(65.8 \%)$ & $4(10.5 \%)$ & & $9(23.7 \%)$ \\
\hline Heavy motorized vehicle (18) & $5(27.8 \%)$ & $5(27.8 \%)$ & & $8(44.4 \%)$ \\
\hline Fixed object (10) & $3(30.0 \%)$ & $3(30.0 \%)$ & & $4(40.0 \%)$ \\
\hline Unknown (3) & $1(33.3 \%)$ & $1(33.3 \%)$ & & $1(33.3 \%)$ \\
\hline
\end{tabular}

* Test for significant difference between the helmeted and non-helmeted group only, Fishers exact test

** ANOVA (analysis of variance) 
Table 2: Head and neck injuries according to helmet use $(n=56)$

\begin{tabular}{|c|c|c|c|}
\hline & Helmet $(n=40)$ & No helmet $(n=16)$ & $p$-value* \\
\hline Skull fracture & $16(40.0 \%)$ & $10(62.5 \%)$ & 0.149 \\
\hline Skull base fracture & $16(40.0 \%)$ & $10(62.5 \%)$ & 0.149 \\
\hline Skull vault fracture & $9(22.5 \%)$ & $9(56.3 \%)$ & 0.025 \\
\hline Facial fracture & $9(22.5 \%)$ & $5(31.3 \%)$ & 0.511 \\
\hline Intracranial bleeding & $23(57.5 \%)$ & $13(81.3 \%)$ & 0.127 \\
\hline Epidural haemorrhage & $1(2.5 \%)$ & $4(25.0 \%)$ & 0.020 \\
\hline Subdural haemorrhage & $8(20.0 \%)$ & $7(43.8 \%)$ & 0.097 \\
\hline Subarachnoidal haemorrhage & $23(57.5 \%)$ & $8(50.0 \%)$ & 0.767 \\
\hline Intracerebral haemorrhage & $6(15.0 \%)$ & $3(18.8 \%)$ & 0.705 \\
\hline Intracerebellar haemorrhage & $2(5.0 \%)$ & $2(12.5 \%)$ & 0.570 \\
\hline Intraventricular haemorrhage & $11(27.5 \%)$ & $3(18.8 \%)$ & 0.734 \\
\hline Intracranial neuronal tissue damage & $23(57.5 \%)$ & $11(68.8 \%)$ & 0.550 \\
\hline Cerebral injury & $16(40.0 \%)$ & $9(56.3 \%)$ & 0.374 \\
\hline Cerebellar injury & $6(15.5 \%)$ & $2(12.5 \%)$ & 1.000 \\
\hline Brainstem injury & $10(25.0 \%)$ & $2(12.5 \%)$ & 0.475 \\
\hline Cervical spine injury & $18(45.0 \%)$ & $3(18.8 \%)$ & 0.770 \\
\hline Dislocation & $9(22.5 \%)$ & $0(0.0 \%)$ & 0.048 \\
\hline Fracture & $8(20.0 \%)$ & $1(6.3 \%)$ & 0.421 \\
\hline Spinal cord injury & $3(7.5 \%)$ & $1(6.3 \%)$ & 1.000 \\
\hline Intramuscular haemorrhage & $16(40.0 \%)$ & $2(12.5 \%)$ & 0.061 \\
\hline
\end{tabular}

* Test for significant difference between the helmeted and non-helmeted group only, Fishers exact test

Table 3: HNISS scores by confirmed injuries $(n=56)$

\begin{tabular}{|c|c|c|c|}
\hline & \multicolumn{3}{|c|}{ Mean HNISS score } \\
\hline & Injury present & No injury & p-value* \\
\hline Skull fracture & 46,00 & 13,70 & $<0,0001$ \\
\hline Skull base fracture & 46,00 & 13,70 & $<0,0001$ \\
\hline Skull vault fracture & 49,67 & 18,76 & $<0,0001$ \\
\hline Facial fracture & 44,43 & 23,45 & $<0,05$ \\
\hline Intracranial bleeding & 39,25 & 9,70 & $<0,0001$ \\
\hline Epidural haemorrhage & 53,80 & 26,24 & $<0,05$ \\
\hline Subdural haemorrhage & 42,27 & 23,73 & $<0,05$ \\
\hline Subarachnoidal haemorrhage & 41,19 & 13,20 & $<0,0001$ \\
\hline Intracerebral haemorrhage & 39,33 & 26,66 & 0,201 \\
\hline Intracerebellar haemorrhage & 57,25 & 26,50 & $<0,05$ \\
\hline Intraventricular haemorrhage & 41,36 & 24,48 & $<0,05$ \\
\hline Intracranial neuronal tissue damage & 44,03 & 5,00 & $<0,0001$ \\
\hline Cerebral injury & 45,00 & 15,55 & $<0,0001$ \\
\hline Cerebellar injury & 46,88 & 25,67 & $<0,05$ \\
\hline Brainstem injury & 63,25 & 19,27 & $<0,0001$ \\
\hline Cervical spine injury & 36,81 & 23,83 & 0,082 \\
\hline Dislocation & 55,22 & 23,62 & $<0,001$ \\
\hline Fracture & 43,56 & 25,85 & 0,072 \\
\hline Spinal cord injury & 38,00 & 27,98 & 0,480 \\
\hline Intramuscular haemorrhage & 34,17 & 26,11 & 0,302 \\
\hline
\end{tabular}

*Analysis of variance, ANOVA 
widespread injuries. The subjects with brainstem injury collectively suffered the highest HNISS mean of 63.25 as this most often is attributed with an AIS 6 score. Interestingly, a total of $18 / 56$ subjects (32.1\%) suffered only minor head and/or cervical spine injuries, which could be illustrated by their HNISS scores ranging from 0-6 (i.e. no single AIS score above 2). Their primary cause of death therefore had to be found elsewhere. Another $11 / 56$ subjects (19.6\%) reached a maximum score of 75 based on their head and/or cervical spine injuries.

Our more detailed examination of data showed that the use of helmet was significantly associated with a decreased incidence of skull vault fractures and epidural haemorrhage. This finding is in agreement with a recent observational study, which showed a $69 \%$ reduction in skull fractures, $71 \%$ reduction in cerebral contusion, and $53 \%$ reduction in intracranial haemorrhage in helmeted motorcyclists ${ }^{15}$. A study by Whyte et al. from $2016{ }^{16}$ of helmeted motorcyclists in fatal crashes similarly showed a higher incidence of skull base fractures than vault fractures, similar to our findings (Table 2). Interestingly, they found inertial brain injuries (e.g. contusion and laceration of the brain and brainstem) to be common despite the use of a helmet. This finding is in agreement with our findings showing intracranial neuronal tissue damage and bleeding in more than $57 \%$ of all cases. Interestingly, we observed 12 cases of brainstem lesions, e.g. rupture or contusion, in which $10(83 \%)$ had used a helmet. A subgroup of these brainstem injuries included six cases of medulla oblongata rupture which was observed exclusively in the helmeted subject group $(p=0.168)$. This suggests, that the brainstem may be particularly vulnerable to excessive direct and indirect loading of the head-neck intersection whilst wearing a helmet during a crash. This is supported by engineering studies, as inertial trauma involving a rotational component has been shown to increase shear stresses around the brainstem increasing the risk of rupture, contusion and bleeding, irrespective of helmet use as this offers limited protection ${ }^{16-19}$. Injuries to the face (fractures only) affected $20 \%$ of the 83 subjects, most often involving the nasal bone, maxilla and mandible. We observed no statistically significant differences between the helmet versus no helmet group. However, subjects suffering a facial fracture more often suffered substantial severe injuries as the HNISS was significantly higher in comparison to the subjects with no facial fractures (Table 3 ).

\section{Cervical spine injuries}

Cervical spine injuries including fractures, dislocations and soft tissue bleeding, were all more frequent in the helmeted group. Fractures and dislocations of the cervical spine affected 15 of the victims (18\%), with dislocations being significantly more common in the helmeted group ( $p=0.048$ ). Furthermore, spinal cord injury was observed in four cases (three of whom used a helmet). These findings add to the discussion concerning potential risk of cervical spine injury associated with helmet use. Although some studies from the 1980'es have found helmet use to be associated with an increased risk of cervical spine injury ${ }^{5 ; 6}$, these have since been refuted in several investigations ${ }^{3 ; 20 ; 2}$. The Cochrane review by Liu et al. ${ }^{3}$ from 2008 found no significant association between helmet use and the risk of neck injury. More recently, Rice et al. ${ }^{20}$ revisited the data from the Hurt Study ${ }^{22}$ using "modern statistical methods", thereby disputing the results by Goldstein on the same data from $19811^{5}$. Actually, Rice et al. ${ }^{20}$ reported a reduced risk of neck injury by $37 \%(p=0.044)$ in their analysis. Hence, the current scientific evidence is in overall favor of no added injury risk to the cervical spine due to helmet use. Therefore, we are cautious not to draw any firm conclusions from our data. Nonetheless, we do find these finding interesting and supportive of the need for further investigations into the potential risk from helmet use on subgroups of cervical spine injury following MC and moped crashes.

\section{Injury prevention}

Interestingly we found that helmet use differed between the groups on transportation, as helmet use was much more common among the $M C$ riders, irrespective of the mandatory use according to the Danish law. A Danish survey in 2008 revealed an average helmet use rate of 95\% among moped riders (mopeds with max. speed of $30 \mathrm{~km} / \mathrm{h}$ ) ${ }^{23}$. The authors also found that females had a higher helmet use rate than males. A later survey from Denmark in 2009 found that $99 \%$ of motorcycle riders used a helmet ${ }^{24}$. In our study population, only $48.2 \%$ of all decedents were confirmed to have used a helmet. The difference between the rate of helmet non-use in our study of MC and moped riders who died in a traffic crash and the prior surveys of all riders is easily explained by bias resulting from the protective effect of helmets; non-helmet wearing riders who crash are substantially more likely to be killed than helmeted riders, all other factors (i.e. crash severity and type) being equal. Of course, prevention of serious injury and death requires not only high/universal rates of helmet use, but also other predictive parameters such as behavioral issues, awareness and speed; factors largely dependent on rider training and education.

\section{Limitations}

The primary limitations of our study were the lack of information regarding the circumstances of the crash (speed of impact and helmet use, in particular), selection bias resulting from the fact that fewer than one in five (19\%) of MC or moped deaths in the catchment area were referred for autopsy (consistent with the rate of autopsy referral for all traffic crash deaths in Denmark) ${ }^{25}$, and a lack of detailed information regarding the duration of post-crash survival of the decedents (potentially affecting the pathology observed on autopsy, e.g. the degree of post-injury haemorrhage). The fact that far more MC than moped-riding decedents were helmeted may serve as a reasonable alternative explanation for the pathological differences between the helmeted and unhelmeted decedents. Generally, motorcycles can attain higher speeds and a higher rate of acceleration than mopeds, and thus the use of a helmet may very well serve as a confounder for the energy of the crash, which may, in turn, affect the distribution, type, and severity of head and neck pathology. Another potential source of bias among the included cases stems from the fact that they were all referred by law enforcement for autopsy, and thus represent a potentially unique subgroup of the total number of MC and moped deaths.

The introduction of routine PMCT of all medicolegal autopsies in 2008 may have influenced the results. Prior to 2008 only $4 / 33$ cases (12.1\%) (2 MC and 2 moped) underwent PMCT whereas all 23 cases from 2008-2017 (20 MC and 3 moped) were examined with PMCT. Hence, a total of 22/27 MC riders (81.5\%) and 5/29 moped riders (17.2\%) were examined with PMCT. Although, a high agreement exist between PMCT and medicolegal autopsy in detecting head and neck injuries, the addition of PMCT findings to the medicolegal autopsy is likely to increase the number of injuries detected ${ }^{26}$ - 
28. For example, facial and cervical spine fractures as well as intraventricular haemorrhage is more likely to be identified on PMCT, whereas discrete fractures and bleeding is better visualised on autopsy ${ }^{26-28}$. Therefore, as most MC riders were examined with PMCT in contrast to the moped riders it is possible that our results underestimate to true occurrence of injuries sustained in the moped group. Nonetheless, as the forensic autopsies prior to 2008 were performed according to the highest standards, and in some cases involved conventional radiological evaluation (unreported percentage) we believe our results represent an accurate description of the injuries present in the decedents.

Our study described the distribution of head and neck injuries according to helmet use in MC and moped crashes with fatal outcomes in a select geographical region of Denmark. Although we would expect that our findings are generalisable to all of Denmark, this may not be the case with regard to other European countries or on different continents.

In this retrospective autopsy study of eighty-three cases of people killed in motorcycle- and moped crashes we found, that the most common lesions in the head and neck were intracranial haemorrhage, intracranial neuronal tissue damage and fractures of the skull. Among the 56 cases examined in detail based on their confirmed helmet use or lack hereof, a significantly lower prevalence of skull vault fractures and epidural haemorrhage was observed in the helmeted cases. However, cervical spine dislocation and brainstem injury was significantly more common in the helmeted cases, possibly a result of higher travel and impact speeds among the helmeted MC riders versus the lower speeds among moped riders. Future practice should emphasise the clear documentation of helmet use of the deceased by the police on-scene, which should be communicated to the forensic pathologist during the autopsy. In addition detailed information regarding the nature and severity of the crash, as well as helmet type, will allow assessment of non-confounded associations with the anatomical distribution, type and severity of observed head and neck injuries. Medicolegal autopsy should be performed in all cases of road traffic crash related deaths in order to allow more precise description of causation and enable improved accident and injury prevention measures.

\section{REFERENCES}

[1] Vejdirektoratet. Trafikulykker for året 2017. Vejdirektoratet 2018.

[2] Færdselssikkerhedskommisionen. Hver ulykke er én for meget - et fælles ansvar. Færdselssikkerhedskommisionens nationale handlingsplan 2013-2020. Rådet for Sikker Trafik 2013, Cool Gray.

[3] Liu BC, Ivers R, Norton R, Boufous S, Blows S, Lo SK. Helmets for preventing injury in motorcycle riders. Cochrane Database Syst Rev 2008;(1):CD004333.

[4] Moskal A, Martin JL, Laumon B. Helmet use and the risk of neck or cervical spine injury among users of motorized two-wheel vehicles. Inj Prev 2008;14(4):238-244.

[5] Goldstein JP. The effect of motorcycle helmet use on the probability of fatality and the severity of head and neck injuries: a latent variable framework. Eval Rev 1986;10(3):355-375.

[6] Krantz KP. Head and neck injuries to motorcycle and moped riders--with special regard to the effect of protective helmets. Injury 1985;16(4):253-258.

[7] Abbreviated Injury Scale 2005 (Update 2008). Association for the Advancement of Automative Medicine 2008, Chicago, IL, USA.

[8] Stoner HB, Heath DF, Yates DW, Frayn KN. Measuring the severity of injury. J R Soc Med 1980;73(1):19-22.

[9] Osler T, Baker SP, Long W. A modification of the injury severity score that both improves accuracy and simplifies scoring. J Trauma 1997;43(6):922-925.

[10] Lavoie A, Moore L, LeSage N, Liberman M, Sampalis JS. The Injury Severity Score or the New Injury Severity Score for predicting intensive care unit admission and hospital length of stay? Injury 2005;36(4):477-483.

(11] Freeman MD, Dobbertin K, Kohles SS, Uhrenholt L, Eriksson A. Serious head and neck injury as a predictor of occupant position in fatal rollover crashes. Forensic Sci Int 2012;222(1-3):228-233.

[12] Danmarks Statistik. Tilskadekomne og dræbte i færdselsuheld efter personskade, indblandede transportmidler, område og tid. Online http://www.statistikbanken.dk accessed October 31, 2018

[13] Auman KM, Kufera JA, Ballesteros MF, Smialek JE, Dischinger PC. Autopsy study of motorcyclist fatalities: the effect of the 1992 Maryland motorcycle helmet use law. Am J Public Health 2002;92(8):1352-1355.

[14] Hitosugi M, Takatsu A, Shigeta A. Injuries of motorcyclists and bicyclists examined at autopsy. Am J Forensic Med Pathol 1999;20(3):251-255.
[15] Singleton MD. Differential protective effects of motorcycle helmets against head injury. Traffic Inj Prev 2017;18(4):387-392.

[16] Whyte T, Gibson T, Anderson R, Eager D, Milthorpe B. Mechanisms of Head and Neck Injuries Sustained by Helmeted Motorcyclists in Fatal Real-World Crashes: Analysis of 47 In-Depth Cases. J Neurotrauma 2016;33(19):1802-1807.

[17] Zhang L, Yang KH, King Al. A proposed injury threshold for mild traumatic brain injury. J Biomech Eng 2004;126(2):226-236.

[18] Huang J, Peng Y, Yang J, Otte D, Wang B. A study on correlation of pedestrian head injuries with physical parameters using in-depth traffic accident data and mathematical models. Accid Anal Prev 2018;119:91-103.

[19] King Al, Yang K, Zhang L, Hardy W, Viano DC. Is head injury caused by linear or angular acceleration? IRCOBI Conference Proceedings 2003. Lissabon, Portugal.

[20] Rice TM, Troszak L, Erhardt T, Trent RB, Zhu M. Novelty helmet use and motorcycle rider fatality. Accid Anal Prev 2017;103:123-128.

[21] Sarkar S, Peek C, Kraus JF. Fatal injuries in motorcycle riders according to helmet use. J Trauma 1995;38(2):242-245.

[22] Hurt HH, Ouellet JV, Thom DR. Motorcycle accidents cause factors and identification of countermeasures: Vol I: Technical Report. 1981. Department of Transportation; Washington DC, US.

[23] Behrensdorff I. Cyklisters brug af cykelhjelm og knallertkøreres brug af styrthjelm i

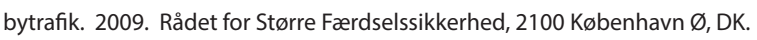

[24] Havarikommissionen for Vejtrafikulykker. Motorcykler. 2009. Havarikommisionen for Vejtrafikulykker, Nofoprint.

[25] Uhrenholt L, Gregersen M. Hvorfor obduceres så få trafikdræbte? Dansk Politi 2003;5:30-31.

[26] Legrand L, Delabarde T, Souillard-Scemama R, Sec I, Plu I, Laborie JM et al. Comparison between postmortem computed tomography and autopsy in the detection of traumatic head injuries. J Neuroradiol 2020;47(1):5-12.

[27] Jacobsen C, Bech BH, Lynnerup N. A comparative study of cranial, blunt trauma fractures as seen at medicolegal autopsy and by computed tomography. BMC Med Imaging 2009;9:18 doi:10.1186/1471-2342-9-18

[28] Uhrenholt L, Boel LW. Contributions from Forensic Imaging to the Investigation of Upper Cervical Fractures. J Forensic Sci 2010;55(6):1598-1602. 